\title{
Pharmacy-Based Opportunistic Atrial Fibrillation Screening at a Community Level: A Real-Life Study
}

\author{
Stephane Olindo ${ }^{1, *}$, Pauline Renou ${ }^{1}$, François Martial ${ }^{2}$, Nathalie Heyvang ${ }^{1}$, Lea Milan ${ }^{1}$, Sylvain Ledure ${ }^{1}$ and \\ François Rouanet ${ }^{1}$
}

check for

updates

Citation: Olindo, S.; Renou, P.;

Martial, F.; Heyvang, N.; Milan, L.;

Ledure, S.; Rouanet, F.

Pharmacy-Based Opportunistic

Atrial Fibrillation Screening at a

Community Level: A Real-Life Study.

Healthcare 2022, 10, 90. https://

doi.org/10.3390/healthcare10010090

Academic Editor: Raffaele

Giordano

Received: 8 December 2021

Accepted: 30 December 2021

Published: 4 January 2022

Publisher's Note: MDPI stays neutral with regard to jurisdictional claims in published maps and institutional affiliations.

Copyright: (C) 2022 by the authors. Licensee MDPI, Basel, Switzerland. This article is an open access article distributed under the terms and conditions of the Creative Commons Attribution (CC BY) license (https:// creativecommons.org/licenses/by/ $4.0 /)$.
1 Stroke Unit Department, University Hospital of Bordeaux, Place Amelie Raba-Leon, CEDEX, 33076 Bordeaux, France; pauline.renou@chu-bordeaux.fr (P.R.); nathalie.heyvang@chu-bordeaux.fr (N.H.); lea.milan@chu-bordeaux.fr (L.M.); sylvain.ledure@chu-bordeaux.fr (S.L.); francois.rouanet@chu-bordeaux.fr (F.R.)

2 Union Régionale des Professionnels de Santé Pharmaciens Nouvelle-Aquitaine, 33000 Bordeaux, France; francois.martial@resopharma.fr

* Correspondence: stephane.olindo@chu-bordeaux.fr; Tel.: +33-557821263
Abstract: Purpose: Opportunistic pharmacy-based screening of atrial fibrillation (AF) appears effective, but the proportion of detected citizens is unknown. The aim of our real-life study was to determine rates of screening in a community population according to age group and gender. Methods: We conducted four community campaigns of pharmacy-based single-time point AF screening that involved individuals $\geq 65$ years. We used a single-lead and hand-held device MyDiagnostick (6229 EV Maastricht, The Netherlands) that generates a 60-s ECG trace. All pharmacies of the communities $(n=54)$ were involved. Rates of screening were assessed on the base of the French National Institute for Statistics and Economic Studies data and were expressed as percentage and 95\% Confidence interval (CI). Results: We screened 4208 individuals (Mean age, $74.2 \pm 6.6$ years; females, $60.2 \%$ ). The screening rate in citizens aged $\geq 65$ years was $17.2 \%$ (16.6-17.7), and higher in females than in males (17.9\% [17.3-18.6] versus 16.0 [15.3-16.8], $p<0.001)$. The 70-74 age group showed the highest rate (25.7\% [24.4-27]) compared to other groups. After 74 years, screening rates decreased steadily with age and dropped to $4.8 \%$ [3.8-6.1] in very elderly ( $\geq 90)$. Among the 188 (4.47\%) positive screening, $117(2.78 \%)$ showed an AF that was unknown in 53 (1.26\%). Increasing age (OR: 1.05 [1.00-1.09], $p=0.04$ ), male sex (OR: 4.30 [2.33-7.92], $p<0.0001$ ) and high CHA2DS2-Vasc (OR: 1.59 [1.21-2.09], $p=0.0008)$ were independent predictors of unknown AF. Conclusion: Single-lead AF detection performed in community pharmacies result in screening one in six elderly citizens. Although male sex and elderly predicted unknown AF diagnosis, they were less involved in such designed campaigns.

Keywords: atrial fibrillation; screening; pharmacy; community; elderly

\section{Introduction}

Atrial fibrillation (AF) is the most common sustained arrythmia and is characterized by a growing prevalence that increases steadily with age [1]. The disease is closely associated with stroke [2], and diagnosis of AF is of the utmost importance since anticoagulation treatment is safe and efficient in preventing ischemic events [3]. Unfortunately, AF is often clinically silent and is frequently underdiagnosed [4]. The European Society of Cardiology (ESC) recommend an opportunistic screening by pulse taking or ECG in patients $\geq 65$ years of age [3]. In recent years, development of mobile health technologies provides opportunities to screen large group of population. Several studies assessed AF detection tools such as watches [5], smartphones [6] or hand-held devices [7]. These trials have been performed in primary care center, geriatric ward or pharmacies [8]. Efficiency in new AF detection deeply differ $(0.7 \%$ to $9.5 \%)$ between opportunistic single-time screening [9] and multi-time screening in selected individuals [10]. Screening tools that record single-lead 
ECG strip of $\geq 30$ s may be particularly useful when they allow ECG trace reviewing by a physician and eventually AF diagnosis [3].

In this report, we assessed our real-life experience of large campaigns of opportunistic AF screening in community pharmacies that focused on unselected customers aged $\geq 65$ years.

\section{Methods}

\subsection{Aim of the Study}

The purpose of our study was to assess a real-life procedure of AF screening involving community pharmacists, general practitioners (GPs) and cardiologists.

\subsection{Design of the Screening Campaigns and Procedure}

Screening campaigns resulted from an initiative of our Stroke Unit and were logistically supported by the URPS Pharmaciens (Union Régionale des Professionnelles de Santé Pharmaciens) and by town councils of the communities. The ARS (Agence Régionale de Santé) Nouvelle Aquitaine funded the project.

Protect-AVC was a single-time-point AF screening implemented in all pharmacies of 4 communities located in the area of Bordeaux. The 4 screening campaigns were sequentially performed from October 2018 to March 2020.

Fifty-four pharmacies agreed to participate. In the 2 weeks preceding campaigns initiation, the population of the communities was informed through local newspapers, town council newsletters, flyers and radio spots that an AF screening was available in their pharmacies. GPs and cardiologists of the campaign area were systematically informed about the procedure of the AF screening.

A face-to-face presentation of the screening procedure was performed with the pharmacists in each participating pharmacy. Briefly, the procedure was as follows:

If they wished to, individuals aged $\geq 65$ years could perform an AF screening in one of the community pharmacies involved in the campaigns. When they had available time, pharmacists could also invite their pharmacy customers to participate to the campaign. With the pharmacist assistance, individuals were asked to fill a short questionnaire that focused on demographic characteristics and on the presence of vascular risk factors such as high blood pressure, diabetes, heart failure, peripheral vascular disease, history of TIA or stroke, known $\mathrm{AF}$, anticoagulation treatment and presence of an implantable pacemaker. The questionnaire was deidentified and only the first letters of participant name and surname were recorded. The name of their GP was also requested and individuals were asked to tick one box if they were against the transmission of the detection result to their GP or against the use of the collected data.

The AF screening was performed with MyDiagnostick device, a hand-held single-lead ECG (Applied Biomedical Systems BV, 6229 EV Maastricht, The Netherlands). The record takes $1 \mathrm{~min}$ and analysis conclusion is immediately displayed by turning either green for normal cardiac rhythm or red for AF detection.

In case of positive AF screening, the captured $60 \mathrm{~s}$ ECG trace was downloaded to the computer and printed by the pharmacist. The participating individual was aware of the need to visit his GP with an envelope containing an information letter, the printed ECG and a return-form questionnaire in a pre-stamped envelope. The GP was also systematically kept informed by post that his patient has participated to the Protect-AVC campaign and has been diagnosed with a probable AF. In France, the GP is the coordinator of the patient pathway and if required he refers his patient to the cardiologist. Thus, the decision to continue cardiac investigations such as a 12-lead ECG, or a $24 \mathrm{~h}$ ECG holter was left to the GP and cardiologist's discretion.

Through the return questionnaire, the GP informed the study team of his conclusion as follows: AF previously unknown, AF previously known, and AF not confirmed.

Data of all filled participant questionnaires, results of the MyDiagnostick screening and of the return questionnaire were collected. 


\subsection{Analysis of the Positive Mydiagnostick ECG Traces}

For all positive screenings, MyDiagnostick ECG trace patterns were analyzed by the two investigators (F.R. and S.O.). Assessment resulted in a classification as follows: AF, sinus rhythm, sinus arrythmia, extrasystoles, motion artefact or undetermined. In case of disagreement, a definitive classification was adjudicated by consensus. Arrythmia and absence of $p$ wave determined AF.

For the study assessment, an unknown AF was defined as: (1) Typical AF on ECG strip and (2) absence of previous AF confirmed by the GP or lack of knowledge of AF by the participant without any anticoagulation treatment at the time of screening.

\section{Statistical Analysis}

Our screening population was stratified by age $(65-69,70-74,75-79,80-84,85-89$ and $\geq 90$ years). The numerator for calculation of screening rate was the number of participants detected in an age group and the denominator was based on the estimation of age structure of the population provided by French National Institute for Statistics and Economic Studies (INSEE). Data were collected on 10 February 2020 through the www.insee.fr link. Age structure data was available for Pessac, Arcachon and Saint-Medard en Jalles (SMEJ) communities. Proportion of screening was expressed as a percentage and the exact $95 \%$ binomial confidence intervals (CI) was used.

The $\chi^{2}$ test and Student $t$ test were used to examine differences in nominal and continuous values. $p$-value of $<0.05$ was considered statistically significant.

A multivariable logistic regression analysis was performed to identify factors predictive of previously unknown AF. Factors of potential significance in univariate analysis (defined as $p<0.1$ ) were introduced into the multivariable model in a backward stepwise manner. Independent factors were expressed as Odd Ratio and 95\% CI.

\section{Individuals Consents}

Individuals were informed of their anonymized participation in this research, and the possibility to withdraw was offered by ticking a box in the short questionnaire that was systematically filled before MyDiagnostick screening.

\section{Data Availability}

Anonymized database used for the current analysis will be available upon written request to the corresponding author from any qualified investigator.

\section{Results}

The four campaigns have screened 4208 individuals aged $\geq 65$ years old. Periods of screening of the four campaigns, numbers and demographic characteristics of detected individuals are summarized in Table 1 . The mean age of screened participants was $74.2 \pm 6.6$ years old and women were prevalent $(60.1 \%)$.

Size and age structure of the population were available in three communities, Pessac, Arcachon and SMEJ, and Figure 1 shows the age pyramid for $\geq 65$ years old people. In the pooled population ( $\geq 65$ years) of the three communities $(n=21,521), 3694$ subjects have participated to the campaign giving a total screening rate of $17.2 \%$ (16.6-17.7). The rate was significantly higher in female than in male (17.9\% [17.3-18.6] versus 16.0 [15.3-16.8], $p<0.001)$. Rates of screening in groups of population aged between 65-69, 70-74, 75-79, $80-84,85-89$ and $\geq 90$ years old and according to gender are described in Table 2 and illustrated in Figures 2 and 3. The 70-74 group showed the significant highest rate (25.7\% [24.4-27]) compared to other groups. Over 74 years old, rates of screening decreased steadily, and the oldest aged group ( $\geq 90$ years old) showed the lowest rate of detection (4.8\% [3.8-6.1]). The screening rates were significantly higher in females than in males in the $65-69$ - and 70-74-years old groups, $18.8 \%$ (17.5-20.1) versus $14.3 \%$ (13.0-15.6) and $30.1 \%$ (28.2-32.0) versus $20.6 \%$ (18.9-22.4), $p<0.001$, respectively. The proportions of population that have been detected in each campaign are described in Supplementary Table S1. 
Table 1. Characteristics of the 4 campaigns of atrial fibrillation screening.

\begin{tabular}{|c|c|c|c|c|c|}
\hline & The 4 Communities & Pessac & North Medoc & Arcachon & $\begin{array}{l}\text { Saint-Medard } \\
\text { En Jalles }\end{array}$ \\
\hline Screening period (date) & $\begin{array}{c}18 \text { October } 2018 \\
\text { to } \\
15 \text { April } 2020\end{array}$ & $\begin{array}{l}18 \text { October } 2018 \\
\text { to } \\
31 \text { August } 2019\end{array}$ & $\begin{array}{c}13 \text { September } 2019 \\
\text { to } \\
15 \text { December } 2019\end{array}$ & $\begin{array}{c}\text { 10 September } 2019 \\
\text { to } \\
\text { 05 January } 2020\end{array}$ & $\begin{array}{c}\text { 04 January } 2020 \\
\text { to } \\
15 \text { April } 2020\end{array}$ \\
\hline $\begin{array}{c}\text { Screening } \\
\text { period (months) }\end{array}$ & - & 10.4 & 3.1 & 3.8 & 3.4 \\
\hline $\begin{array}{l}\text { Number of pharmacies } \\
\text { involved }(n)\end{array}$ & 54 & 18 & 14 & 11 & 11 \\
\hline $\begin{array}{l}\text { Individuals } \geq 65 \text { y.o. } \\
\quad \text { screened }(n)\end{array}$ & 4208 & 1570 & 514 & 1124 & 1000 \\
\hline $\begin{array}{c}\text { Mean number of } \\
\text { screenings per month }\end{array}$ & - & 148.1 & 165.8 & 288.2 & 294.1 \\
\hline $\begin{array}{l}\text { Mean number of } \\
\text { screenings } \\
\text { per pharmacy }\end{array}$ & 77.9 & 87.2 & 36.7 & 102.2 & 90.9 \\
\hline $\begin{array}{l}\text { Population } \geq 65 \text { y.o. in } \\
\text { the community }(n)\end{array}$ & - & 10,143 & - & 5503 & 5875 \\
\hline $\begin{array}{c}\text { Age, y.o., } \\
\text { mean } \pm \text { Standard } \\
\text { deviation (Range) }\end{array}$ & $\begin{array}{l}74.2 \pm 6.6 \\
(65-100)\end{array}$ & $\begin{array}{l}74 \pm 6.6 \\
(65-100)\end{array}$ & $\begin{array}{l}74 \pm 6.2 \\
(65-100)\end{array}$ & $\begin{array}{l}74.3 \pm 6.8 \\
(65-100)\end{array}$ & $\begin{array}{l}73.6 \pm 6.3 \\
(65-95)\end{array}$ \\
\hline Female (\%) & 60.2 & 62.1 & 52.5 & 60.5 & 60.8 \\
\hline $\begin{array}{c}\text { Positive Screening, } \\
n(\%)\end{array}$ & $188(4.47)$ & $65(4.14)$ & $31(6.03)$ & $60(5.33)$ & $32(3.20)$ \\
\hline $\begin{array}{l}\text { Positive Screening in } \\
\text { relation with Atrial } \\
\text { Fibrillation } n(\%)\end{array}$ & $117(2.78)$ & $38(2.42)$ & $19(3.69)$ & $38(3.38)$ & $22(2.20)$ \\
\hline
\end{tabular}

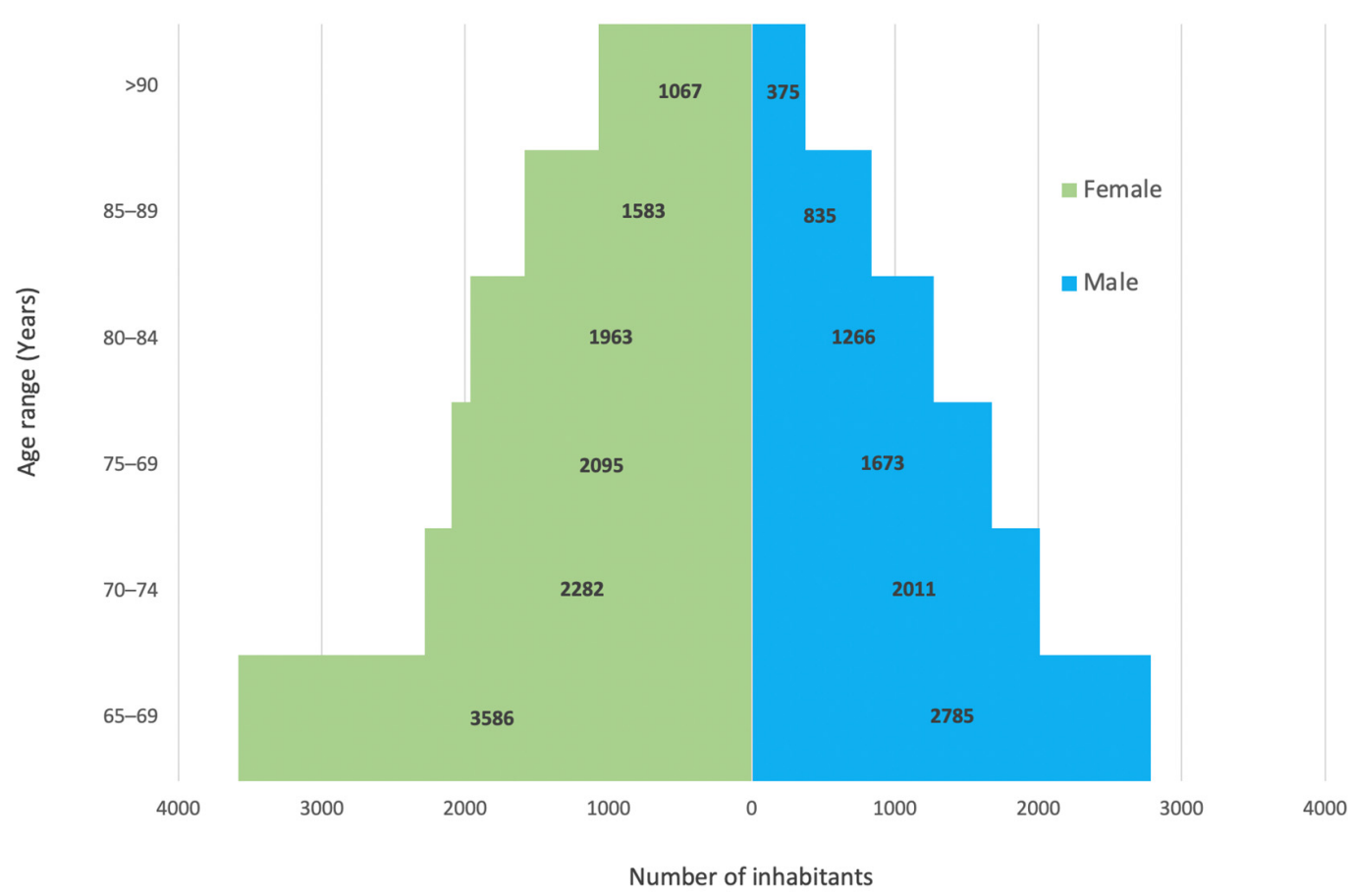

Figure 1. Age pyramid of the pooled population $\geq 65$ years old of the 3 screened communities. 
Table 2. Rates of screening according to age group and gender in the pooled population of 3 communities.

\begin{tabular}{ccccc}
\hline Age Group (Years) & All & Female & Male & $p$ \\
\hline $65-69$ & $16.8(15.9-17.8)$ & $18.8(17.5-20.1)$ & $14.3(13.0-15.6)$ & $<0.001$ \\
\hline $70-74$ & $25.7(24.4-27.0)$ & $30.1(28.2-32.0)$ & $20.6(18.9-22.4)$ & $<0.001$ \\
\hline $75-79$ & $19.9(18.6-21.2)$ & $20.7(19.0-22.5)$ & $18.8(16.9-20.7)$ & 0.120 \\
\hline $80-84$ & $13.7(12.5-14.9)$ & $13.1(11.7-14.7)$ & $14.5(12.6-16.5)$ & 0.280 \\
\hline $85-89$ & $10.8(9.6-12.1)$ & $10.2(8.8-11.8)$ & $11.9(9.8-14.3)$ & 0.200 \\
\hline$\geq 90$ & $4.8(3.8-6.1)$ & $3.9(2.9-5.3)$ & $7.2(4.9-10.4)$ & 0.016 \\
\hline$\geq 65$ & $17.2(16.6-17.7)$ & $17.9(17.3-18.6)$ & $16.0(15.3-16.8)$ & $<0.001$ \\
\hline
\end{tabular}

Rates of screening are expressed as percentage and 95\% Confidence Intervals. Statistical Comparison was performed between female and male groups.

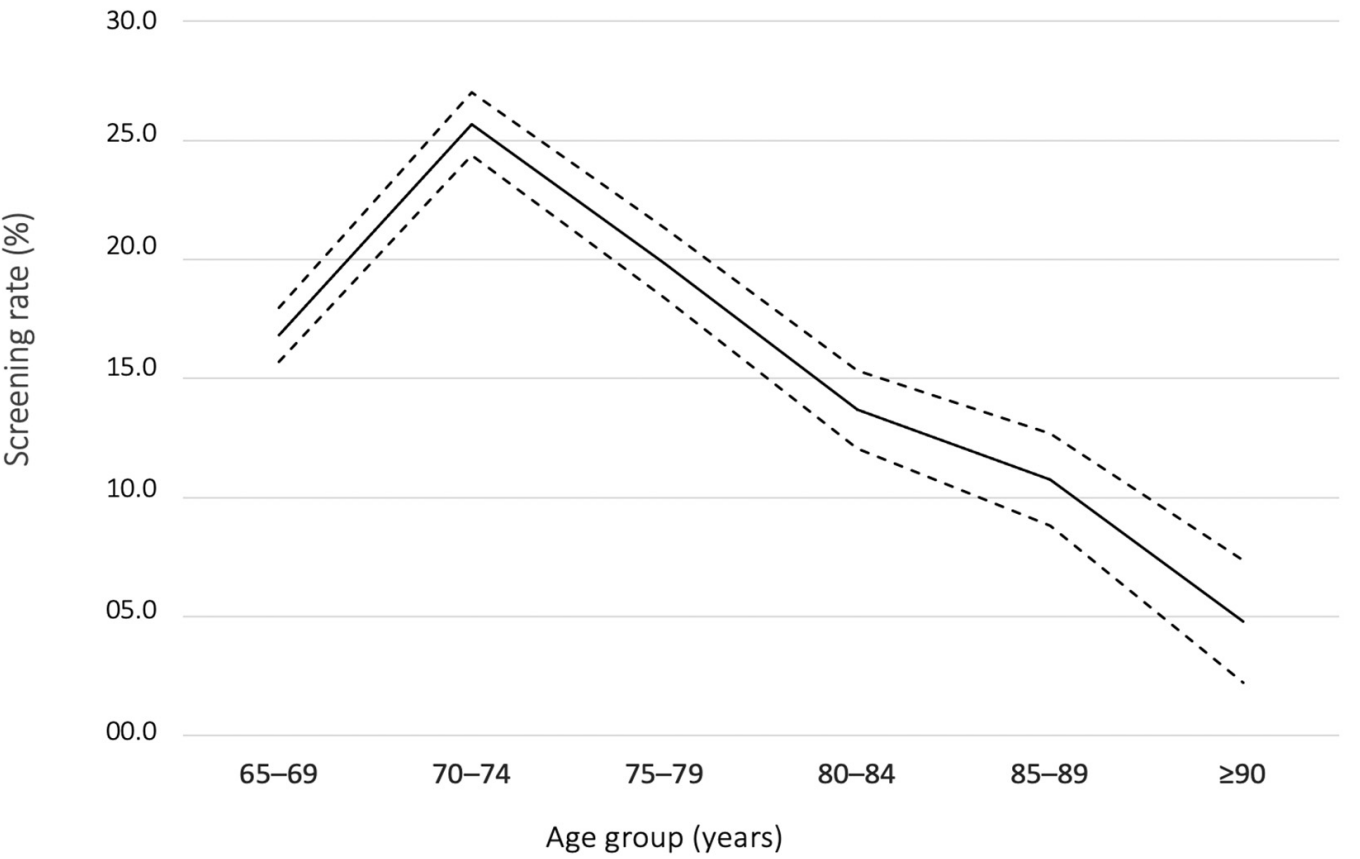

Figure 2. Atrial Fibrillation screening rates according to age group for all participants. The continuous line represents the value of the screening rate in percentage and dotted lines show the upper and lower limits of the $95 \%$ confidence interval.

The Pessac campaign was performed over the longest period of time (10.5 months) compared to the three other campaigns which screened individuals between 3.1 and 3.8 months. The rate of detection in the Pessac population was similar to those found in Arcachon or SMEJ and $83 \%$ of the total screening was performed during the first 4.5 months.

A total of $188(4.47 \%)$ individuals were screened positive. The analysis of the singlelead ECG generated by MyDiagnostick device revealed a typical AF pattern in 117 cases $(2.78 \%)$, extrasystoles in six cases $(0.14 \%)$, motion artefacts in 56 cases $(1.33 \%)$ and undetermined in nine cases $(0.21 \%)$. Among the $117 \mathrm{AF}$ individuals, $53(1.26 \%)$ had an unknown $\mathrm{AF}$ and 64 suffered from a known AF (1.52\%) (Figure 4). A total of $70(1.7 \%)$ participants reported wearing an implanted pacemaker. In this subgroup, $13(18.6 \%)$ were screened positive including 10 with a previously known $\mathrm{AF}$ and three positive screening related to artifacts. No previously unknown AF was detected in subjects with implanted pacemakers. In the whole studied population, the rates of unknown AF detection tend to increase with age group, but the differences were only significant for the comparison between 65-69 and older age groups (Supplementary Table S2). 


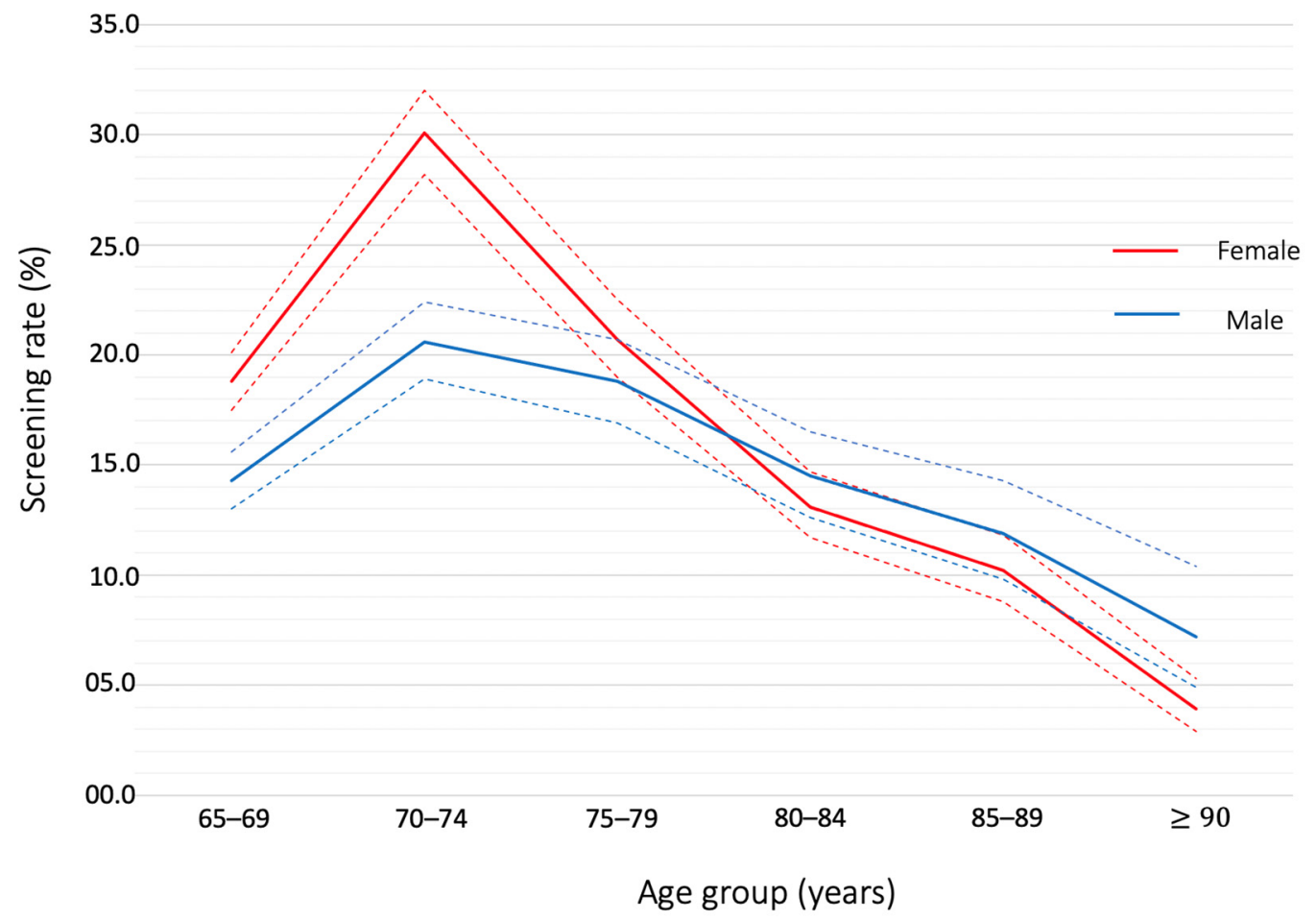

Figure 3. Atrial Fibrillation screening rates according to age group and gender. The continuous line represents the value of the screening rate in percentage and dotted lines show the upper and lower limits of the $95 \%$ confidence interval.

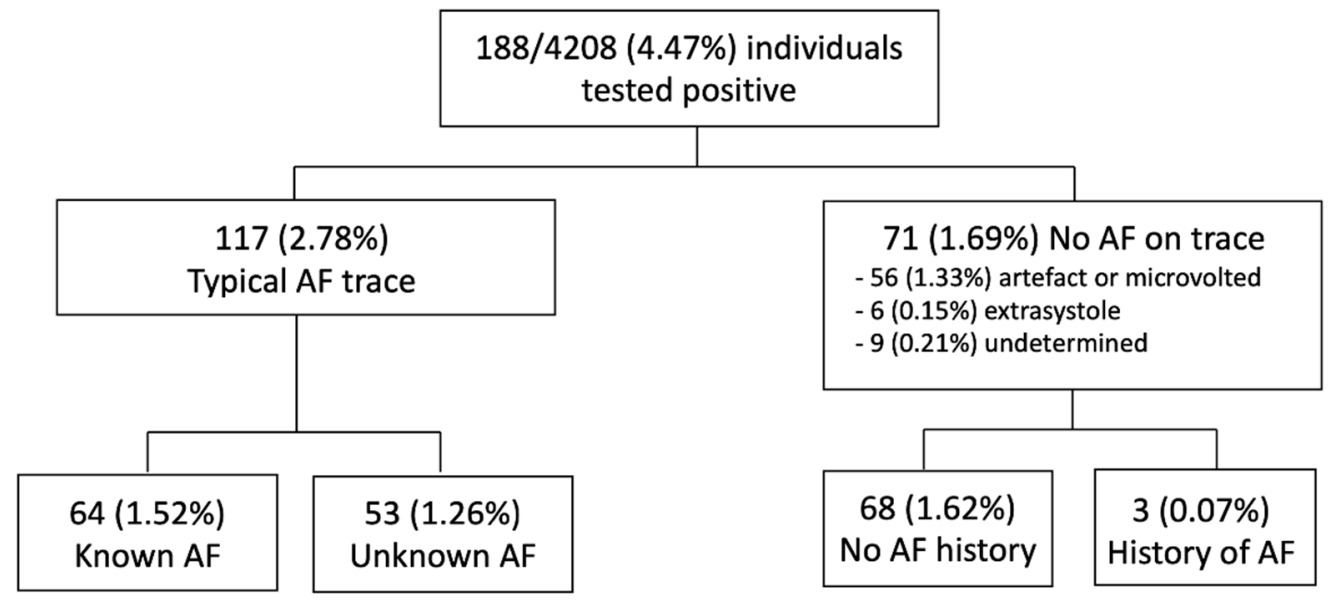

Figure 4. Flow chart of participants in the study.

Compared to the negative screening group, unknown $\mathrm{AF}$ individuals were older $(77.7 \pm 6.2$ vs. $73.9 \pm 6.5, p<0.0001)$ and predominantly males $(61.5 \%$ vs. $39.3 \%, p<0.0001)$. They showed a higher prevalence of diabetes $(18.9 \%$ vs. $9.5 \%, p=0.03)$ and history of heart failure $(15.9 \%$ vs. $6.3 \%, p=0.02)$ and had a higher CHA2-DS2-Vasc score $(3.17 \pm 1.03$ vs. $2.68 \pm 1.05, p=0.001)$. Multivariable analysis found that increasing age (OR: 1.05, 95\% CI [1.00-1.09], $p=0.04$ ), male sex (OR: 4.30, 95\% CI [2.33-7.92], $p<0.0001$ ) and high CHA2DS2-Vasc (OR: 1.59, 95\% CI [1.21-2.09], $p=0.0008$ ) were independent predictors of unknown AF (Table 3). 
Table 3. Characteristics of positive screening with unknow AF and negative screening participants. Uni- and multi-variable analysis.

\begin{tabular}{|c|c|c|c|c|c|c|}
\hline & \multirow{2}{*}{$\begin{array}{c}\text { Unknown AF } \\
\text { Participants } N=53\end{array}$} & \multirow{2}{*}{$\begin{array}{l}\text { Negative Screening } \\
\text { Participants } N=4020\end{array}$} & \multicolumn{2}{|c|}{ Univariable Analysis } & \multicolumn{2}{|c|}{ Multivariable Analysis } \\
\hline & & & $\begin{array}{l}\text { Odd Ratio } \\
\text { (95\% CI) }\end{array}$ & $p$ & $\begin{array}{l}\text { Odd Ratio } \\
\text { (95\% CI) }\end{array}$ & $p$ \\
\hline $\begin{array}{l}\text { Age (years), } \\
\text { mean } \pm S D\end{array}$ & $77.7 \pm 6.2$ & $73.9 \pm 6.5$ & $1.08(1.04-1.12)$ & $<0.0001$ & $1.05(1.00-1.09)$ & 0.0400 \\
\hline Male & $35(66.0)$ & $1584(39.4)$ & $2.99(1.69-5.30)$ & 0.0002 & $4.30(2.33-7.92)$ & $<0.0001$ \\
\hline Arterial Hypertension & $27(50.9)$ & $1757(43.7)$ & $1.34(0.78-2.30)$ & 0.29 & & \\
\hline Diabetes & $10(18.9)$ & $380(9.5)$ & $2.23(1.11-4.47)$ & 0.02 & & \\
\hline History of Stroke & $3(6.1)$ & $186(4.6)$ & $1.26(0.39-4.09)$ & 0.69 & & \\
\hline $\begin{array}{l}\text { History of } \\
\text { Heart failure }\end{array}$ & 7 (15.9) & $240(6.3)$ & $2.39(1.07-5.36)$ & 0.03 & & \\
\hline $\begin{array}{c}\text { Peripheral } \\
\text { arterial disease }\end{array}$ & $5(10.2)$ & $177(4.6)$ & $2.26(0.89-5.75)$ & 0.08 & & \\
\hline CHA2DS2Vasc & $3.17 \pm 1.03$ & $2.68 \pm 1.05$ & $1.49(1.18-1.88)$ & 0.0008 & $1.59(1.21-2.09)$ & 0.0008 \\
\hline
\end{tabular}

Nominal values are expressed as number (percentage). AF: Atrial Fibrillation.

In summary, the main findings of the study are: (1) Our procedure resulted in screening $17.2 \%$ (16.6-17.7) of individuals $\geq 65$ years of a community population. (2) The $70-74$ years age group showed the highest AF screening rate (25.7\% [24.4-27]), then rates steadily declined with increasing age until $4.8 \%(2.2-7.4)$ in the very elderly population ( $\geq 90$ years old). (3) The screening rate was significantly lower in males than in females in the 65-69- and 70-74-years age groups, $14.3 \%$ (12.5-16.0) versus $18.8 \%(17.3-20.3)$ and $20.6 \%$ (18.6-22.6) versus $30.1 \%$ (28.4-31.9), respectively. 4) Rates of previously unknown AF diagnosed during the campaigns was $1.26 \%(0.93-1.62)$.

\section{Discussion}

We report real-life data of large campaigns of opportunistic AF screening setting in community pharmacies. The screening campaigns focused on unselected customers aged $\geq 65$ years old and detection was performed by MyDiagnostick, a hand-held single-lead ECG device.

We found a previously unknown AF in $1.26 \%$ of screened individuals. This rate is in line with results disclosed in a recent meta-analysis [8] of studies using single-lead ECG devices or Holter monitoring. The mean AF screening rate was assessed at $1.7 \%$. In single-time point detection studies, the rate was around $1 \%$ ranging from $0.5 \%$ [9] to $5.3 \%$ [11] in a selected group of individuals with a large proportion of post-stroke condition. In accordance with previous studies [12,13], individuals with new AF were more likely to be older and male, to have medical history of diabetes and of heart failure, and to score a higher CHA2DS2-Vasc. Old age, male-sex and higher CHA2DS2-Vasc score constituted independent factors of unknown AF detection.

Several single-lead AF screening trials have been performed in community pharmacies (Table 4) [6,7,14-17]. However, no data is available regarding the proportion of people detected in a population community included in an AF screening pharmacy program. We found that AF detection campaigns setting in pharmacies allowed to screen one in six $(17.2 \%)$ individuals of a community aged $\geq 65$ years. This proportion reached one in four $(25.7 \%)$ subjects in the 70-74 years age group. The rate decreased steadily with age, and the age group $\geq 90$ years showed the lowest rate $(4.8 \%)$. It may reflect that oldest population poorly visit the community pharmacies due to mobility impairment. Additionally, increasing age is associated with nursing home living due to medical condition. Although very elderly individuals are most at risk of AF, they are poorly involved in community pharmacy screening program. Alternative strategies in very elderly should be based on at home screening design. 
Table 4. Summary of trials investigating AF detection using single-lead ECG devices and setting in pharmacies.

\begin{tabular}{|c|c|c|c|c|c|c|c|c|}
\hline Study & Country & $\mathbf{N}$ & Individuals & Device & $\begin{array}{l}\text { Mean/Median } \\
\text { Age (Years) }\end{array}$ & Females (\%) & $\begin{array}{c}\text { New } \\
\text { AF }(n)\end{array}$ & $\begin{array}{l}\text { Rate of New } \\
\text { AF (\%) }\end{array}$ \\
\hline Lowres et al. (2014) & Australia & 1000 & Unselected & Alive Cor & $76 \pm 7$ & 56 & 15 & 1.5 \\
\hline Twigg et al. (2016) & $\begin{array}{l}\text { United } \\
\text { Kingdom }\end{array}$ & 594 & $\begin{array}{c}\text { Unselected } \\
\text { pharmacy customer }\end{array}$ & Alive Cor & $68.3 \pm 8.9$ & - & 5 & 0.8 \\
\hline $\begin{array}{c}\text { Alves da } \\
\text { Costa et al. (2020) }\end{array}$ & 10 countries & 1741 & $\begin{array}{c}\text { Unselected } \\
\text { pharmacy customer }\end{array}$ & Alive Cor & $69.6 \pm 13$ & 67.3 & 5 & 0.57 \\
\hline Savickas et al. (2020) & $\begin{array}{l}\text { United } \\
\text { Kingdom }\end{array}$ & 604 & $\begin{array}{c}>65 \text { years and } \\
\text { attending an influenza } \\
\text { vaccination }\end{array}$ & Alive Cor & $73(69-78)$ & 57.3 & 4 & 0.7 \\
\hline Zaprutko et al. (2020) & Poland & 525 & $\begin{array}{l}\text { Unselected pharmacy } \\
\text { customer > } 65 \text { years }\end{array}$ & Alive Cor & $73.7 \pm 6.5$ & 68.2 & 7 & 1.33 \\
\hline Zink et al. (2021) & Germany & 7107 & $\begin{array}{l}\text { Unselected pharmacy } \\
\text { customer }>65 \text { years }\end{array}$ & MyDiagnostick & $74 \pm 5.9$ & 58 & 256 & 3.6 \\
\hline
\end{tabular}

\section{AF: Atrial Fibrillation}

Whereas male sex was an independent predictor of unknown AF detection, men were less involved than women in the pharmacy screening program $(16.0 \%$ [15.3-16.8] versus $17.9 \%$ [17.3-18.6]). It was particularly significant for the youngest population with a difference that reached $10 \%$ for the $70-74$ years age group (20.6\% [18.9-22.4] versus 30.1\% [28.2-32.0]). Reasons for the gender difference are not clear. It is admitted that compared to women, men have a lower health literacy that is defined as skills to promote and maintain good health through access to, understanding and use of specific information [18]. Campaigns of prevention such as influenza vaccination also show that males are less involved than females [19]. According to social habits, men may visit pharmacies less often to collect treatment or to buy drugstore items.

In our study, rates of screened population did not differ between the three community campaigns. Interestingly, the longest campaign in the Pessac community did not screen a higher proportion of population than the shortest campaigns in the Arcachon and SMEJ communities. Therefore, we assume that repeated short-time campaigns of detection may be preferred to continuous screening.

AF screening campaigns in community pharmacy may constitute an effective primary prevention strategy mostly in the 65-79 years old population. Indeed, distribution of pharmacies throughout the national territory allows large AF screening in general population particularly in non-urban areas where shortage of medical doctor is increasingly significant. Additionally, compared with pulse palpation or no detection, opportunistic AF screening implemented in pharmacies has been considered to be cost-effective in UK [16]. On the other hand, screening disease induces anxiety in participants and the psychological harm results in being labelled with an unexpected disease diagnosis [20]. Pharmacists who participate to the screening campaigns may need to strengthen their knowledge on pathophysiology and on communication particularly in disclosing information according to the detection result.

\section{Limitations of the Study}

The present work has several limitations. Among the 117 participants who showed an AF on the single-lead ECG trace, a definitive conclusion by the GP was obtained for only 68 (58.1\%). However, unknown AF made sense since it was retained in participants who were not treated with anticoagulation and not aware of AF. Assessment of screened population proportion did not take into account the exact address location of the participants and proportion may have been overestimated. Conversely, individuals who live at the municipality border may used to visit pharmacies of another community and then underestimate the screening rate. Screening rates reported in our study could not be applied in other countries with different healthcare organization. The strength of our study is based on collection of 
prospective data from large real-life campaigns with involvement of all pharmacies of the participated communities.

\section{Conclusions}

Real-life screening campaigns setting in community pharmacies allow to identify previously unknow AF in $1.26 \%$. The population aged between 65 and 79 years old is the preferred target. The procedure is associated with a screening gap for elderly individuals and males. Alternative design of detection such as at home screening should be developed for elderly individuals and strategy of information focusing on male population may be proposed.

Supplementary Materials: The following supporting information can be downloaded at: https: // www.mdpi.com/article/10.3390/healthcare10010090/s1, Table S1: Rate of screening according to age group population in the 3 communities; Table S2: Rate of unknown AF according to age group.

Author Contributions: Conceptualization, S.O., F.M., F.R.; methodology, S.O., P.R. and F.R.; validation, S.O., P.R., F.M. and F.R.; formal analysis, S.O.; investigation, S.O., F.R., N.H., L.M. and S.L.; data curation, S.O., N.H., L.M. and S.L.; writing-original draft preparation, S.O.; writing-review and editing, S.O. and F.R.; funding acquisition, S.O. and F.R. All authors have read and agreed to the published version of the manuscript.

Funding: This work was supported by Agence Regional de Santé Nouvelle Aquitaine.

Informed Consent Statement: Informed consent was obtained from all subjects involved in the study.

Data Availability Statement: Data that support the study results could be obtained upon request from the following email: stephane.olindo@chu-bordeaux.fr.

Acknowledgments: Authors thanks municipal authorities of the communities and all pharmacists involved in the screening campaigns. Additional thanks are addressed to V. Lecocq, S. Dubois, P. Meynard, M. Chauveau and I. Barcos for their important technical assistance.

Conflicts of Interest: The authors declare no conflict of interest.

\section{References}

1. Colilla, S.; Crow, A.; Petkun, W.; Singer, D.E.; Simon, T.; Liu, X. Estimates of Current and Future Incidence and Prevalence of Atrial Fibrillation in the U.S. Adult Population. Am. J. Cardiol. 2013, 112, 1142-1147. [CrossRef] [PubMed]

2. Wolf, P.A.; Abbott, R.D.; Kannel, W.B. Atrial fibrillation as an independent risk factor for stroke: The Framingham Study. Stroke 1991, 22, 983-988. [CrossRef] [PubMed]

3. Hindricks, G.; Potpara, T.; Dagres, N.; Arbelo, E.; Bax, J.J.; Blomström-Lundqvist, C.; Boriani, G.; Castella, M.; Dan, G.-A.; Dilaveris, P.E.; et al. 2020 ESC Guidelines for the diagnosis and management of atrial fibrillation developed in collaboration with the European Association for Cardio-Thoracic Surgery (EACTS): The Task Force for the diagnosis and management of atrial fibrillation of the European Society of Cardiology (ESC) Developed with the special contribution of the European Heart Rhythm Association (EHRA) of the ESC. Eur. Heart J. 2021, 42, 373-498. [PubMed]

4. Flaker, G.C.; Belew, K.; Beckman, K.; Vidaillet, H.; Kron, J.; Safford, R.; Mickel, M.; Barrell, P.; The Affirm Investigators. Asymptomatic atrial fibrillation: Demographic features and prognostic information from the Atrial Fibrillation Follow-up Investigation of Rhythm Management (AFFIRM) study. Am. Heart J. 2005, 149, 657-663. [CrossRef]

5. Perez, M.V.; Mahaffey, K.W.; Hedlin, H.; Rumsfeld, J.S.; Garcia, A.; Ferris, T.; Balasubramanian, V.; Russo, A.M.; Rajmane, A.; Cheung, L.; et al. Large-Scale Assessment of a Smartwatch to Identify Atrial Fibrillation. N. Engl. J. Med. 2019, 381, 1909-1917. [CrossRef] [PubMed]

6. Lowres, N.; Neubeck, L.; Salkeld, G.; Krass, I.; McLachlan, A.J.; Redfern, J.; Bennett, A.A.; Briffa, T.; Bauman, A.; Martinez, C.; et al. Feasibility and cost-effectiveness of stroke prevention through community screening for atrial fibrillation using iPhone ECG in pharmacies. Thromb. Haemost. 2014, 111, 1167-1176. [CrossRef] [PubMed]

7. Zink, M.D.; Mischke, K.G.; Keszei, A.P.; Rummey, C.; Freedman, B.; Neumann, G.; Tolksdorf, A.; Frank, F.; Wienströer, J; Kuth, N.; et al. Screen-detected atrial fibrillation predicts mortality in elderly subjects. EP Eur. 2021, 23, 29-38. [CrossRef]

8. Ramkumar, S.; Nerlekar, N.; D'Souza, D.; Pol, D.J.; Kalman, J.M.; Marwick, T.H. Atrial fibrillation detection using single lead portable electrocardiographic monitoring: A systematic review and meta-analysis. BMJ Open 2018, 8, e024178. [CrossRef]

9. Chan, N.Y.; Choy, C.C.; Chan, C.K.; Siu, C.W. Effectiveness of a nongovernmental organization-led large-scale community atrial fibrillation screening program using the smartphone electrocardiogram: An observational cohort study. Hear Rhythm 2018, 15, 1306-1311. [CrossRef] 
10. Hendrikx, T.; Rosenqvist, M.; Wester, P.; Sandström, H.; Hörnsten, R. Intermittent short ECG recording is more effective than 24-hour Holter ECG in detection of arrhythmias. BMC Cardiovasc. Disord. 2014, 14, 41. [CrossRef]

11. Samol, A.; Masin, M.; Gellner, R.; Otte, B.; Pavenstädt, H.J.; Ringelstein, E.B.; Reinecke, H.; Waltenberger, J.; Kirchhof, P. Prevalence of unknown atrial fibrillation in patients with risk factors. EP Eur. 2013, 15, 657-662. [CrossRef]

12. Benjamin, E.J.; Levy, D.; Vaziri, S.M.; D'Agostino, R.B.; Belanger, A.J.; Wolf, P.A. Independent risk factors for atrial fibrillation in a population-based cohort: The Framingham Heart Study. JAMA 1994, 271, 840-844. [CrossRef]

13. Staerk, L.; Wang, B.; Preis, S.R.; Larson, M.G.; Lubitz, S.A.; Ellinor, P.T.; McManus, D.D.; Ko, D.; Weng, L.-C.; Lunetta, K.L.; et al. Lifetime risk of atrial fibrillation according to optimal, borderline, or elevated levels of risk factors: Cohort study based on longitudinal data from the Framingham Heart Study. BMJ 2018, 361, k1453. [CrossRef] [PubMed]

14. Twigg, M.J.; Thornley, T.; Scobie, N. Identification of patients with atrial fibrillation in UK community pharmacy: An evaluation of a new service. Int. J. Clin. Pharm. 2016, 38, 784-787. [CrossRef] [PubMed]

15. da Costa, F.A.; Mala-Ladova, K.; Lee, V.; Tous, S.; Papastergiou, J.; Griffiths, D.; Chaumais, M.-C.; Hersberger, K.E.; Viola, R.; Paulino, E.; et al. Awareness campaigns of atrial fibrillation as an opportunity for early detection by pharmacists: An international cross-sectional study. J. Thromb. Thrombolysis 2020, 49, 606-617. [CrossRef] [PubMed]

16. Savickas, V.; Stewart, A.J.; Rees-Roberts, M.; Short, V.; Bhamra, S.K.; Corlett, S.A.; Mathie, A.; Veale, E.L. Opportunistic screening for atrial fibrillation by clinical pharmacists in UK general practice during the influenza vaccination season: A cross-sectional feasibility study. PLoS Med. 2020, 17, e1003197. [CrossRef] [PubMed]

17. Zaprutko, T.; Zaprutko, J.; Baszko, A.; Sawicka, D.; Szałek, A.; Dymecka, M.; Telec, W.; Kopciuch, D.; Ratajczak, P.; Michalak, M.; et al. Feasibility of Atrial Fibrillation Screening with Mobile Health Technologies at Pharmacies. J. Cardiovasc. Pharmacol. Ther. 2019, 25, 142-151. [CrossRef]

18. Rikard, R.V.; Thompson, M.S.; McKinney, J.; Beauchamp, A. Examining health literacy disparities in the United States: A third look at the National Assessment of Adult Literacy (NAAL). BMC Public Health 2016, 16, 975. [CrossRef]

19. Applewhite, A.; Stancampiano, F.F.; Harris, D.M.; Manaois, A.; Dimuna, J.; Glenn, J.; Heckman, M.G.; Brushaber, D.E.; Sher, T.; Valery, J.R. A Retrospective Analysis of Gender-Based Difference in Adherence to Influenza Vaccination during the 2018-2019 Season. J. Prim. Care Community Health 2020, 11, 2150132720958532. [CrossRef] [PubMed]

20. Cotter, A.R.; Vuong, K.; Mustelin, L.L.; Yang, Y.; Rakhmankulova, M.; Barclay, C.J.; Harris, R.P. Do psychological harms result from being labelled with an unexpected diagnosis of abdominal aortic aneurysm or prostate cancer through screening? A systematic review. BMJ Open 2017, 7, e017565. [CrossRef] [PubMed] 